\section{BLOOD CARDIOPLEGIA ENHANCED WITH NITRIC OXIDE DONOR SPM-5185 COUNTERACTS POSTISCHEMIC ENDOTHELIAL AND VENTRICULAR DYSFUNCTION}

This study tested the hypothesis that enhancement of blood cardioplegia with the nitric oxide donor agent SPM-5185 inhibits postischemic left ventricular and coronary endothelial dysfunction. Eighteen anesthetized dogs supported by total vented bypass were subjected to 30 minutes of normothermic ischemia followed by $4^{\circ} \mathrm{C}$ multidose blood cardioplegia. Hearts received either standard blood cardioplegia (vehicle group; $n=6$ ), blood cardioplegia with $1 \mu \mathrm{mol} / \mathrm{L}$ SPM-5185 (low-dose group; $n=6$ ), or $10 \mu \mathrm{mol} / \mathrm{L}$ SPM-5185 (high-dose group; $n=6$ ). After 60 minutes of cardioplegic arrest, the heart was reperfused for a total of 60 minutes, first in the beating empty state for $\mathbf{3 0}$ minutes and then after discontinuation of bypass for 30 minutes. Baseline and postischemic left ventricular function was assessed by the slope of the end-systolic pressure-volume (impedance catheter) relation. Postischemic end-systolic pressure-volume relation was depressed by $53.7 \%$ of preischemic values in the vehicle group (from $8.2 \pm 1.0$ to $3.8 \pm 0.3 \mathrm{~mm} \mathrm{Hg} / \mathrm{ml}$ ) and by $33.7 \%$ (from $9.2 \pm 1.1$ to $6.1 \pm 0.5 \mathrm{~mm} \mathrm{Hg} / \mathrm{ml}$ ) in the low-dose group. In contrast, there was complete postischemic functional recovery in the high-dose group (from $7.6 \pm 1.1$ to $7.2 \pm 1.2 \mathrm{~mm} \mathrm{Hg} / \mathrm{ml}$ ). In coronary arteries isolated from these hearts, endotheliumdependent maximal relaxation to acetylcholine was impaired by $27 \%$ in the vehicle group and by $18 \%$ in the low-dose group, whereas the high-dose group showed complete endothelium-dependent relaxation. Myeloperoxidase activity, an index of neutrophil accumulation in postischemic myocardium, was elevated in the vehicle and low-dose groups $(3.36 \pm 0.58$ and $2.56 \pm 0.68 \mathrm{U} / 100 \mathrm{mg}$ tissue $)$ but was significantly reduced in the high-dose group to $1.27 \pm 0.45 \mathrm{U} / 100 \mathrm{mg}$ tissue. We conclude that inclusion of $10 \mu \mathrm{mol} / \mathrm{L}$ nitric oxide donor SPM-5185 in blood cardioplegia improves postischemic ventricular performance and endothelial function in ischemically injured hearts, possibly via inhibition of neutrophil-mediated damage. (J Thorac Cardrovasc SuRg 1995;109:1146-54)

Katsuhiko Nakanishi, MD, Zhi-Qing Zhao, PhD, J. Vinten-Johansen, PhD, Dudley A. Hudspeth, MD, D. Scott McGee, BS, and John W. Hammon, Jr., MD, Winston-Salem, N.C.
T here is increasing evidence that myocardial ischemia and reperfusion cause coronary endothelial damage, which results in a decreased release or production of endothelium-derived relaxing factor from the vascular endothelium. ${ }^{1-4}$ Endothelium-

From the Department of Cardiothoracic Surgery, Bowman Gray School of Medicine of Wake Forest University, WinstonSalem, N.C.

Supported in part by grant HL46179 (Dr. Vinten-Johansen) from the Heart, Lung and Blood Institute of the National Institutes of Health.

Received for publication March 17, 1994.

Accepted for publication August 22, 1994.

Address for reprints: Jakob Vinten-Johansen, PhD, Department of Cardiothoracic Surgery, Bowman Gray School of Medicine, Medical Center Blvd., Winston-Salem, NC 27157-1096.

Copyright (C) 1995 by Mosby-Year Book, Inc.

$0022-5223 / 95 \$ 3.00+0 \quad \mathbf{1 2 / 1 / 6 0 1 4 1}$ derived relaxing factor is identical to nitric oxide $(\mathrm{NO})^{5}$ or a nitroso-containing compound and has various physiologic properties including vasodilation, inhibition of platelet aggregation ${ }^{6}$ and neutrophil adhesion, ${ }^{7}$ and biradical quenching of superoxide anions. ${ }^{8,9}$ Because neutrophil activation and oxygen radicals have been implicated as major mechanisms of myocardial ischemia-reperfusion injury, ${ }^{10}$ attenuation of NO release caused by endothelial damage after reperfusion may exacerbate the extent of postischemic injury and may be a critical mechanism in the dynamics of myocardial ischemia-reperfusion injury. ${ }^{4}$

In the development of myoprotective strategies with the use of cardioplegic solutions, attention has been primarily focused on protecting myocytes from morphologic injury and contractile dysfunction. However, recent studies have demonstrated the extreme vulnerability of endothelial cells to post- 
ischemic (reperfusion) injury. ${ }^{4,11} \mathrm{~A}$ recent study from our laboratory showed that neither brief normothermic global ischemia nor cardioplegic arrest with blood cardioplegia (BCP) in the absence of reperfusion impaired coronary endothelial function. ${ }^{12}$ However, endothelial damage was manifested only after unmodified blood reperfusion after removal of the aortic crossclamp, with or without intervening cardioplegia. Cardioplegic solutions could be an ideal vehicle for the introduction of agents that target the perpetrators of endothelial injury during elective cardiac arrest and subsequent reperfusion. Replacement of lost (secondary to endothelial damage) endogenous $\mathrm{NO}$ with authentic $\mathrm{NO},{ }^{13}$ an exogenous NO donor, or supplementation with the precursor of NO (that is, L-arginine) may prevent endothelial damage and pathologic sequelae. ${ }^{4,14}$

This study tested the hypothesis that the NO donor compound SPM-5185 used in blood cardioplegia would attenuate endothelial dysfunction and preserve postischemic left ventricular function in the dog subjected to normothermic ischemia, multidose $\mathrm{BCP}$, and reperfusion.

\section{Material and methods}

Surgical procedure. Surgical and cardiopulmonary bypass procedures have been described in detail elsewhere. ${ }^{12,15}$ Heartworm-free adult mongrel dogs of either sex weighing 18.9 to $26.6 \mathrm{~kg}$ (average $22.1 \pm 1.3 \mathrm{~kg}$ ) were anesthetized with intravenous sodium thiamylal $(20 \mathrm{mg} /$ $\mathrm{kg})$ followed by fentanyl citrate $(350 \mu \mathrm{g})$ and diazepam $(5 \mathrm{mg})$ as needed during the experiment. After median sternotomy and heparinization $(300 \mathrm{U} / \mathrm{kg}$, supplemented every 90 minutes), the left subclavian artery was cannulated and the pericardium was incised and tented. A Millar MPC-500 temperature-compensating solid-state catheter (Millar Instruments, Houston, Tex.) was placed in the proximal aorta through the right internal mammary artery. The left ventricle was instrumented to measure instantaneous pressure (Millar MPC-500) and volume (Webster 7F octapolar catheter, Anaheim, Calif.) as described previously. ${ }^{15}$

The superior and inferior venae cavae were transatrially cannulated and the venous return cannulas temporarily posed in the right atrium to prevent obstruction of venous return while the circulation was intact. Three to five sets of preischemic left ventricular function data were acquired during a 12 -second period of respiratory apnea by transiently occluding the superior and inferior venae cavae with the snares. This resulted in a gradual time-varying reduction in sequential pressure-volume loops from which systolic and diastolic functional parameters were derived (see following sections). ${ }^{15,16}$ Cardiopulmonary bypass was instituted with the use of a Sarns membrane oxygenator model 9443 (Sarns/3M, Ann Arbor, Mich.) primed with 1.5 L hetastarch (Hespan; DuPont Pharmaceutical, Wilmington, Del.). The left and right ventricles were vented by direct cannulation and gravity drainage. Finally, a doublelumen aortic root cannula (DPL, Inc., Grand Rapids, Mich.) was inserted for delivery of BCP and simultaneous measurement of $\mathrm{BCP}$ infusion pressure.

The aorta was crossclamped to initiate unmodified normothermic ischemia for 30 minutes, and mean aortic pressure was maintained at 60 to $70 \mathrm{~mm} \mathrm{Hg}$. A myocardial temperature probe (Shiley, Irvine, Calif.) was placed in the anterior and posterior walls of the left ventricle. Sodium bicarbonate was used to counteract acidemia and maintain arterial $\mathrm{pH}$ between 7.35 and 7.45.

Experimental protocol (Fig. 1). After 30 minutes of normothermic global ischemia, multidose hypothermic BCP arrest was initiated with a 4:1 ratio of BCP solution delivered by a Buckberg-Shiley system (Shiley, Inc.) and the cold induction technique as previously described. ${ }^{15,16}$ The dogs were randomly divided into three groups on the basis of the exclusion or inclusion of the cysteine-containing NO donor compound SPM-5185 in BCP solution. In the vehicle group (VEH, $n=10$ ), unmodified standard BCP solution was used (Table I). In another group, low-dose SPM-5185 (SPM-L, $n=7$ ) was added to BCP solution to achieve a final concentration of $1 \mu \mathrm{mol} / \mathrm{L}$. In the third group, high-dose SPM-5185 (SPM-H, $n=7$ ) was added to BCP solution to achieve a final concentration of $10 \mu \mathrm{mol} / \mathrm{L}$. Systemic rewarming to $37^{\circ} \mathrm{C}$ was achieved and the crossclamp was removed immediately after completion of the terminal BCP infusion.

Reperfusion. After removal of the aortic crossclamp, mean aortic pressure was gradually increased from $50 \mathrm{~mm}$ $\mathrm{Hg}$ to $80 \mathrm{~mm} \mathrm{Hg}$ after electromechanical reanimation was observed. When ventricular fibrillation occurred, directcurrent countershocks of 10 watt-seconds were applied. The heart was maintained in the total vented bypass state for the initial 30 minutes of reperfusion. Systemic blood $\mathrm{Ca}^{2+}$ was corrected to baseline values, and the dog was weaned off bypass for an additional 30 minutes with the heart in the working state. After functional data were acquired at the end of 60 minutes of reperfusion, the heart was excised for the subsequent study of endothelial function by the coronary ring-organ bath technique..$^{12}$ The excised hearts from each group were immediately immersed in cold Krebs-Henseleit solution with the following composition (millimolars per liter): $118 \mathrm{NaCl}, 4.7 \mathrm{KCl}$, $1.2 \mathrm{KH}_{2} \mathrm{PO}_{4}, 1.2 \mathrm{MgSO}_{4}, 2.5 \mathrm{CaCl}_{2}, 12.5 \mathrm{NaHCO}_{3}$, and 10 glucose.

The dogs were handled in compliance with the "Guide for the Care and Use of Laboratory Animals" published by the National Institutes of Health (NIH Publication No. 85-23, revised 1985). The institutional Animal Care and Use Committee approved the study protocol.

Data acquisition and analysis. Analog hemodynamic data were recorded on a microcomputer system (IBM-PC AT) by use of an analog-to-digital converter (Data Translation, model DT2821, Marlboro, Mass.) sampling at 250 $\mathrm{Hz}$ and analyzed with use of an interactive videographics program developed in our laboratory. ${ }^{17}$ Left ventricular chamber conductance was converted to volume with use of the Leycom Sigma 5 signal conditioner and processor (Oegstgeest, The Netherlands). The conductivity of blood was measured periodically throughout the experiment. Parallel conductance volume $\left(V_{p}\right)$ was determined in 


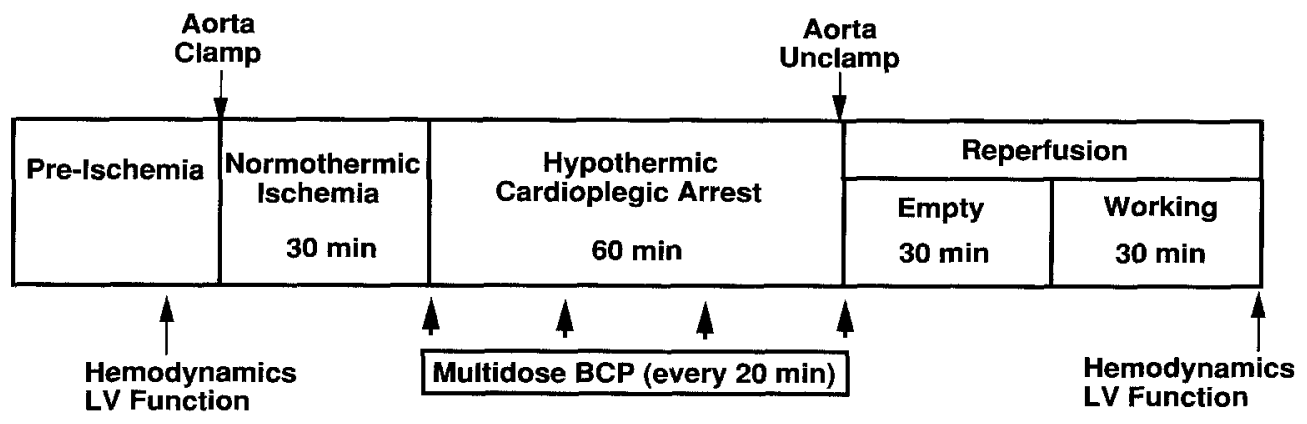

Fig. 1. Experimental protocol. Hearts placed on cardiopulmonary bypass were subjected to 30 minutes of normothermic global ischemia followed by 60 minutes of hypothermic cardioplegic arrest with multidose BCP (every 20 minutes). Thirty minutes were allowed for reperfusion in beating empty state, after which bypass was discontinued to convert heart to working state for another 30 minutes. Hemodynamic and left ventricular $(L V)$ function data were obtained during baseline and after 60 minutes of reperfusion.

Table I. Composition of blood cardioplegia

\begin{tabular}{|c|c|}
\hline Constituent & $\overline{\text { Value }}$ \\
\hline $\begin{array}{l}\text { Potassium ion }(\mathrm{KCl}) \\
(\mathrm{mmol} / \mathrm{L})\end{array}$ & $\begin{array}{c}20-25 \text { (induction, terminal infusions) } \\
10 \text { (intermittent infusions) }\end{array}$ \\
\hline $\begin{array}{l}\text { Calcium ion }(\mathrm{CPD}) \\
(\mathrm{mmol} / \mathrm{L})\end{array}$ & 0.3 \\
\hline $\begin{array}{l}\text { Magnesium ion (derived } \\
\text { from blood) }(\mathrm{mmol} / \mathrm{L})\end{array}$ & 0.5 \\
\hline $\mathrm{pH}$ (THAM buffer) & $8.2\left(\right.$ at $\left.4^{\circ} \mathrm{C}\right)$ \\
\hline Osmolality $(\mathrm{mOsm} / \mathrm{L})$ & $360-380$ \\
\hline Hematocrit (\%) & $14-18$ \\
\hline $\begin{array}{l}\text { Oxygen content } \\
\left(\mathrm{ml} \mathrm{O} \mathrm{O}_{2} / 100 \mathrm{ml}\right)\end{array}$ & $8-10$ \\
\hline
\end{tabular}

$C P D$, Citrate-phosphate-dextrose (blood); THAM, tris(hydroxymethyl)aminomethane.

triplicate at baseline and after ischemia by the bolus hypertonic saline technique and subtracted from the instantaneous total volume signal to obtain the corrected instantaneous absolute left ventricular blood volume.

Calculations

End-systolic pressure-volume relation (ESPVR). Left ventricular systolic performance was described by ESPVR derived from the instantaneous pressure-volume data as described previously. ${ }^{15,18} \mathrm{~V}_{\mathrm{MID}}$, the volume calculated when end-systolic pressure $\left(\mathrm{P}_{\mathrm{es}}\right)$ was within the physiologic range ( 80 to $100 \mathrm{~mm} \mathrm{Hg}$ ), was used as a descriptor of the position of the ESPVR. ${ }^{18}$ The value of $\mathrm{P}_{\mathrm{es}}$ chosen to derive $V_{M I D}$ was consistent within each experiment.

Preload recruitable stroke work (PRSW). Left ventricular stroke work (SW) was calculated by point-by-point integration of left ventricular pressure and volume ( $S W=\int P$ $\cdot \mathrm{dV})$, where $\mathbf{P}$ is left ventricular instantaneous pressure and $\mathrm{dV}$ is rate of volume changes. ${ }^{19}$ Regression analysis was performed to fit stroke work for each loop to its corresponding end-diastolic volume $\left(\mathrm{V}_{\mathrm{cd}}\right)$ using the equation

$$
\mathrm{SW}=\mathrm{M}_{\mathrm{SW}}\left(\mathrm{V}_{\mathrm{ed}}-\mathrm{V}_{\mathrm{SW}, \mathrm{O}}\right)
$$

where $M_{S w}$ is the slope of the linear $S W-V_{e d}$ relation and $V_{\mathrm{SW}, \mathrm{O}}$ is the volume intercept where $\mathrm{SW}=0 \mathrm{~mm} \mathrm{Hg}$ $\cdot \mathrm{mm}$.

End-diastolic pressure-volume relation. The exponential end-diastolic pressure-volume was used to determine the characteristics of left ventricular chamber stiffness (the inverse of compliance) as previously described. ${ }^{15}$ The exponential $\beta$ coefficient is the unitless modulus of chamber stiffness used to describe the degree of curvature of the end-diastolic pressure-volume relation.

In vitro coronary ring studies. Both the left anterior descending coronary artery and the left circumflex coronary artery were carefully dissected from the heart and placed in cold Krebs-Henseleit solution and cleaned of adipose and connective tissue. The isolated left anterior descending and circumflex artery segments were each cut into four rings of approximately $3 \mathrm{~mm}$ in length, mounted on stainless steel hooks, placed in organ chambers filled with Krebs-Henseleit solution $\left(37^{\circ} \mathrm{C}\right.$, gassed with $95 \% \mathrm{O}_{2}$ and $5 \% \mathrm{CO}_{2}$ ), and connected to force transducers (Radnoti model TR 001, Monrovia, Calif.). The rings were allowed to equilibrate at a passive tension of $1 \mathrm{gm}$. After 60 minutes of equilibration, the optimal length-tension relationship was determined by progressively stretching the rings and recording the maximal contractile response to $30 \mathrm{mmol} / \mathrm{L}$ dose of potassium chloride. The rings were incubated with indomethacin $10 \mu \mathrm{mol} / \mathrm{L}$ and precontracted with U46619 $10 \mathrm{nmol} / \mathrm{L}$ (Upjohn Co., Kalamazoo, Mich.), a thromboxane $A_{2}$ mimetic agent, and doserelaxation responses to acetylcholine, A23187, and acidified $\mathrm{NaNO}_{2}$ were determined as previously described. ${ }^{12}$ Drug concentrations are expressed as final concentrations in the organ chambers.

Plasma creatine kinase activity. Blood samples for the measurement of creatine kinase activity were withdrawn from the femoral artery and the plasma separated by centrifugation and analyzed spectrophotometrically as described previously. ${ }^{20}$ Creatine kinase activity was expressed in international units per microgram of protein. 
Table II. Myocardial temperature and delivery volume of $B C P$ at each infusion

\begin{tabular}{|c|c|c|c|c|c|c|}
\hline \multirow[b]{2}{*}{ Time } & \multicolumn{3}{|c|}{ Myocardial temperature $\left({ }^{\circ} \mathrm{C}\right)$} & \multicolumn{3}{|c|}{$B C P$ volume $(\mathrm{ml})$} \\
\hline & $V E H$ & $S P M-L$ & $S P M-H$ & $V E H$ & $S P M-L$ & $S P M-H$ \\
\hline Ischemia & $36.4 \pm 0.1$ & $36.3 \pm 0.4$ & $36.3 \pm 0.2$ & - & - & - \\
\hline Induction & $12.8 \pm 1.0^{*}$ & $13.5 \pm 0.5^{*}$ & $14.0 \pm 1.2^{*}$ & $584 \pm 39$ & $488 \pm 28$ & $513 \pm 52$ \\
\hline $20 \mathrm{~min}$ & $14.1 \pm 0.8^{*}$ & $14.0 \pm 0.5^{*}$ & $13.4 \pm 0.7^{*}$ & $189 \pm 15^{*}$ & $218 \pm 16^{*}$ & $213 \pm 25^{*}$ \\
\hline $40 \mathrm{~min}$ & $12.8 \pm 0.8^{*}$ & $14.9 \pm 0.6^{*}$ & $13.6 \pm 0.8^{*}$ & $209 \pm 22^{*}$ & $179 \pm 19^{*}$ & $209 \pm 28$ \\
\hline $60 \mathrm{~min}$ & $33.6 \pm 0.6$ & $29.4 \pm 1.4$ & $32.7 \pm 0.5$ & $413 \pm 45$ & $368 \pm 25$ & $468 \pm 41$ \\
\hline
\end{tabular}

${ }^{*} p<0.05$ versus unstarred time periods within each group.

Cardiac myeloperoxidase (MPO) activity. Tissue samples weighing approximately $0.2 \mathrm{gm}$ were taken from the anterior and posterior walls of the left ventricle for measurement of MPO activity as an assessment of neutrophil accumulation in myocardium. ${ }^{21}$ The activity of MPO was measured spectrophotometrically and expressed as units per $100 \mathrm{mg}$ tissue. One unit of MPO activity was defined as the quantity of enzyme degrading $1 \mu \mathrm{mol}$ of peroxide per minute at $25^{\circ} \mathrm{C}$.

Statistical analysis. All data were analyzed with the Statistical Analysis System program (PC-SAS, SAS Institute, Cary, N.C.). Time-related differences and grouptime interactions of ESPVR and PRSW parameters and creatine kinase activity were analyzed by two-way analysis of variance for repeated measures adjusted for baseline values. BCP variables, isolated coronary ring data, and MPO data were compared among the three groups by one-way analysis of variance. A value of $p<$ 0.05 was considered statistically significant. All data were presented as means plus or minus standard error of the mean.

\section{Results}

Three dogs in the VEH group could not be weaned off bypass because of severe left ventricular failure during reperfusion. One dog from each SPM-5185 group was excluded because of persistent arrhythmias. Eighteen dogs (6 from each group) were entered into the final data analysis.

Myocardial temperature and delivery of BCP solution (Table II). Myocardial temperatures achieved during both normothermic ischemia and cardioplegic infusion were comparable among groups. The volumes of BCP solution delivered in each group were comparable at each infusion interval. Significantly greater volumes of BCP solution were delivered during induction and 60 minutes of arrest compared with those delivered during the 20and 40-minute intermittent infusions.

ESPVR. All three groups were comparable at the preischemic period in slope $\left(\mathrm{E}_{\mathrm{es}}\right)$, volume-axis intercept $\left(\mathrm{V}_{\mathrm{o}}\right)$, and the midrange volume-axis intercept $\left(V_{M I D}\right)$ of the ESPVR (Fig. 2). In the VEH group, postischemic $\mathrm{E}_{\mathrm{es}}$ was significantly decreased by $48 \%$ from its preischemic value. In the SPM-L group, there was a $30 \%$ decrease in $\mathrm{E}_{\mathrm{es}}$ from baseline levels $(p<0.05)$, but postischemic $\mathrm{E}_{\mathrm{es}}$ tended to be greater than that in the $\mathrm{VEH}$ group. In contrast, postischemic $\mathrm{E}_{\mathrm{es}}$ was not significantly different from its preischemic value in the SPM-H group and was significantly greater than that in the VEH group. Postischemic $V_{o}$ values tended to be less than the corresponding preischemic values in all groups, but there were no statistically significant differences between preischemic and postischemic values. These changes in $V_{o}$ are consistent with a pivotal shift in the ESPVR. Although postischemic $V_{\text {MID }}$ significantly increased compared with the preischemic value in the VEH group, there were no statistically significant differences in postischemic $V_{\text {MID }}$ among the three groups because of counterbalancing changes in $E_{e s}$ and $V_{o}$.

PRSW. The PRSW as an index of integrated systolic and diastolic left ventricular performance agreed with the results observed with ESPVR (Table III). The VEH group showed depressed postischemic performance, manifested as a $26.5 \%$ decrease in the slope of PRSW from baseline. In contrast, the postischemic slope of PRSW in the SPM-L group demonstrated only a slight depression $(6.6 \%)$ compared with baseline values. Interestingly, the SPM-H group showed increased slope of PRSW after reperfusion compared with the baseline value.

Chamber stiffness. Preischemic chamber stiffness was comparable among groups (VEH, $0.035 \pm$ 0.007; SPM-L, $0.032 \pm 0.010$; SPM-H, $0.013 \pm$ 0.009). Postischemic end-diastolic chamber stiffness tended to be higher than baseline values in all groups. However, chamber stiffness was not significantly different between baseline and postischemic values in any group (VEH, $0.046 \pm 0.004$; SPM-L, $0.054 \pm 0.006$; SPM-H, $0.028 \pm 0.015$ ). There were no differences in baseline or postischemic chamber stiffness values among groups.

Plasma creatine kinase activity. There were no significant differences among groups in plasma cre- 

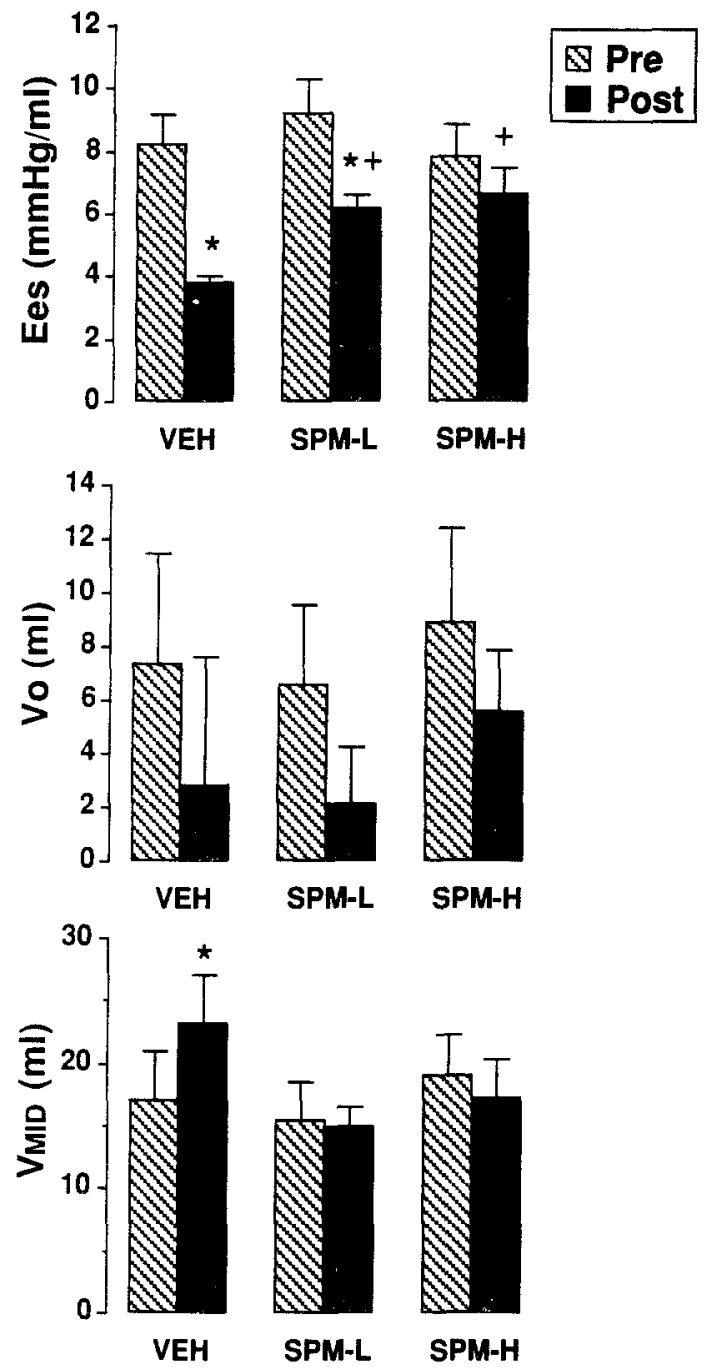

Fig. 2. Variables describing analysis of systolic function by ESPVR in preischemic (Pre) and postishemic (Post) period. Top panel, Slope of ESPVR $\left(\mathrm{E}_{\mathrm{es}}\right)$. Middle panel, Volume axis intercept of ESPVR $\left(\mathrm{V}_{\mathrm{o}}\right)$. Bottom panel, Volume axis value $\left(V_{\mathrm{MD}}\right)$ at $\mathbf{P}_{\mathrm{es}}$ within physiologic range $(80$ to $100 \mathrm{~mm} \mathrm{Hg}$ ), describing position of ESPVR. Asterisk, $p<0.05$ versus preischemic period; plus sign, $p<0.05$ versus VEH.

atine kinase activities at baseline (Table IV). None of the three groups showed an elevation of creatine kinase activities after 30 minutes of normothermic ischemia and 60 minutes of BCP arrest. After blood reperfusion, however, plasma creatine kinase activities were increased in all groups but without significant group differences.

Cardiac MPO activity. There were no differences in MPO activities between anterior and posterior walls in each group, so the samples were pooled. MPO activities in the SPM-H group were signifi-

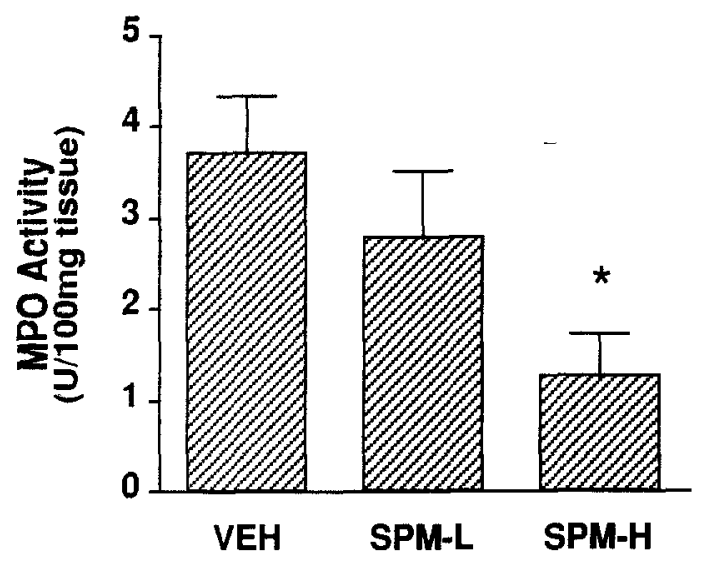

Fig. 3. MPO activity, an index of neutrophil accumulation in postischemic myocardial tissue samples from each group. Asterisk, $p<0.05$ versus VEH.

cantly less than those in the VEH group (Fig. 3). There were no significant differences in MPO activities between the SPM-L and SPM-H groups. These data indicate that high concentrations of SPM-5185 treatment reduced neutrophil accumulation in the myocardium subjected to ischemia and reperfusion compared with no SPM-5185 treatment.

In vitro coronary ring data. Relaxation data from isolated left anterior descending and circumflex coronary arterial rings were statistically similar and were pooled (Fig. 4). The endothelium-dependent receptor-mediated vasodilator acetylcholine caused relaxations in a concentration-dependent manner in all three groups. However, differences in the magnitude of response were observed among groups. The concentration response curves to acetylcholine in the VEH and SPM-L groups were markedly shifted to the right with a reduction in the maximum relaxation compared with that in the SPM-H group. In addition, the maximum responses to acetylcholine in the SPM-H group were significantly greater than those in the VEH group. The endotheliumdependent nonreceptor-mediated vasodilator A23187 also caused concentration-dependent relaxation in all three groups. Responses to the second concentration of A23187 $(0.005 \mu \mathrm{mol} / \mathrm{L})$ in the SPM-H group were significantly greater than those in the VEH and SPM-L groups. In addition, responses to the fourth concentration of A23187 $(0.0125 \mu \mathrm{mol} / \mathrm{L})$ in the SPM-L and SPM-H groups were significantly greater than those in the VEH group. However, responses to other concentrations of A23187 were comparable among the groups, with complete relaxations at higher concentrations of A23187 in all three groups. 
Table III. Summary of variables describing analysis of systolic performance by the PRSW index, which integrates systolic function and diastolic characteristics, and diastolic chamber stiffness by $\beta$ coefficient at preischemic and postischemic periods

\begin{tabular}{|c|c|c|c|c|c|c|}
\hline \multirow[b]{2}{*}{ Group } & \multicolumn{2}{|c|}{$M_{S W}(m m H g \cdot m l / m l)$} & \multicolumn{2}{|c|}{$V_{S W, O}(m l)$} & \multicolumn{2}{|c|}{$\beta$ Coefficient } \\
\hline & Pre & Post & Pre & post & Pre & Post \\
\hline VEH & $65.02 \pm 6.24$ & $47.84 \pm 6.30^{*} \dagger$ & $16.33 \pm 4.23$ & $18.65 \pm 3.79$ & $0.035 \pm 0.007$ & $0.047 \pm 0.004$ \\
\hline SPM-L & $71.18 \pm 11.18$ & $66.50 \pm 6.21$ & $13.96 \pm 3.62$ & $13.81 \pm 1.87$ & $0.032 \pm 0.011$ & $0.054 \pm 0.006$ \\
\hline SPM-H & $50.51 \pm 4.76$ & $67.57 \pm 5.80$ & $17.31 \pm 2.88$ & $15.35 \pm 3.30$ & $0.013 \pm 0.009$ & $0.028 \pm 0.015$ \\
\hline
\end{tabular}

$\mathrm{M}_{S W}$ Slope of PRSW relation; $\mathrm{V}_{S W, O}$ volume axis intercept of the PRSW relation; Pre, preischemic period; Post, postischemic period.

${ }^{*} p<0.05$ versus preischemic period.

$\dagger p<0.05$ versus SPM-H.

Responses to the endothelium-independent vasodilator sodium nitrite showed no impairment and no differences among the groups with any concentration of sodium nitrite. These data indicate that high-dose SPM-5185 protects endothelial function from ischemia and reperfusion damage and that endothelium-dependent nonreceptor-mediated responses and smooth muscle function remain almost intact after ischemia and reperfusion.

Relation between recovery of $\mathbf{E}_{\mathrm{es}}$ and responses to acetylcholine. To evaluate the relationship between the extent of left ventricular functional recovery and endothelial function, the percent recovery of postischemic $\mathrm{E}_{\mathrm{es}}$ and maximum relaxation to acetylcholine from each dog were plotted. The recovery of $E_{\text {es }}$ and responses to acetylcholine were only modestly correlated $(r=0.36, p=0.46)$. The equation for this relationship is $y=0.50 x+22.1$, where $y=$ percent functional recovery and $x=$ percent maximum relaxation. There was only a mild tendency for the recovery of ventricular performance and endothelial function to be correlated.

\section{Discussion}

The effect of chemical cardioplegia on endothelial cell structure and function is controversial. Earlier studies have shown that crystalloid cardioplegia and BCP cause endothelial damage, ${ }^{22-25}$ whereas other studies found that endothelial damage was prevented by the use of $\mathrm{BCP} .{ }^{22,25}$ Our recent study demonstrated that functional and morphologic damage to the coronary vascular endothelium in injured hearts was manifest not during chemical cardioplegia, but rather during subsequent blood reperfusion. ${ }^{12}$ The results from the present study show that an organic NO donor compound, SPM5185 , used as an adjunctive agent to BCP, prevented postischemic endothelial injury and attenuated postischemic left ventricular dysfunction in a dose-
Table IV. Plasma creatine kinase activity (international units per microgram protein) during the time course of the experiment

\begin{tabular}{lrrccc}
\hline Group & Preischemia & \multicolumn{1}{c}{ Ischemia } & $B C P$ & Reperfusion \\
\hline VEH & $10.43 \pm 1.91$ & $11.85 \pm 1.82$ & $14.85 \pm 2.03$ & $24.11 \pm 3.95$ \\
SPM-L & $8.93 \pm 1.83$ & $9.69 \pm 1.02$ & $12.55 \pm 0.37$ & $29.62 \pm 6.33$ \\
SPM-H & $7.80 \pm 1.21$ & $8.75 \pm 1.17$ & $12.65 \pm 1.95$ & $16.83 \pm 1.93$
\end{tabular}

Ischemia, After 30 minutes of normothermic ischemia; $B C P$, after last (60 minutes) delivery of blood cardioplegia; reperfusion, after a total of 60 minutes of reperfusion after removal of aortic crossclamp.

dependent manner in dogs subjected to normothermic global ischemia, cardioplegic arrest, and reperfusion. Whereas the VEH and SPM-L groups demonstrated $52 \%$ and $30 \%$ depressions of postischemic systolic performance assessed by ESPVR, respectively, the SPM-H group reversed this postischemic contractile dysfunction. In addition, endothelium-dependent relaxations to acetylcholine were impaired in the isolated coronary arteries from the VEH and SPM-L groups, with maximum relaxations being $78 \%$ and $90 \%$, respectively. On the other hand, postischemic coronary arteries from the SPM-H group showed significantly better relaxation to acetylcholine (maximum relaxation 108\%). The recovery of systolic function assessed by ESPVR and the maximum relaxation responses to acetylcholine were only moderately correlated. A reduction in neutrophil accumulation in the SPM-H group sug." gests a neutrophil mechanism of cardioprotection. Although SPM-5185 is a vasodilator, there was no increase in cardioplegia volume delivery to contribute to better myocardial preservation.

One of the major findings in the present study is that neutrophil accumulation in the myocardium (assessed by MPO activity) was reduced in the SPM-H group, which suggests an antineutrophil mechanism for SPM-5185. Neutrophil activation and adherence to the coronary vascular endothe- 

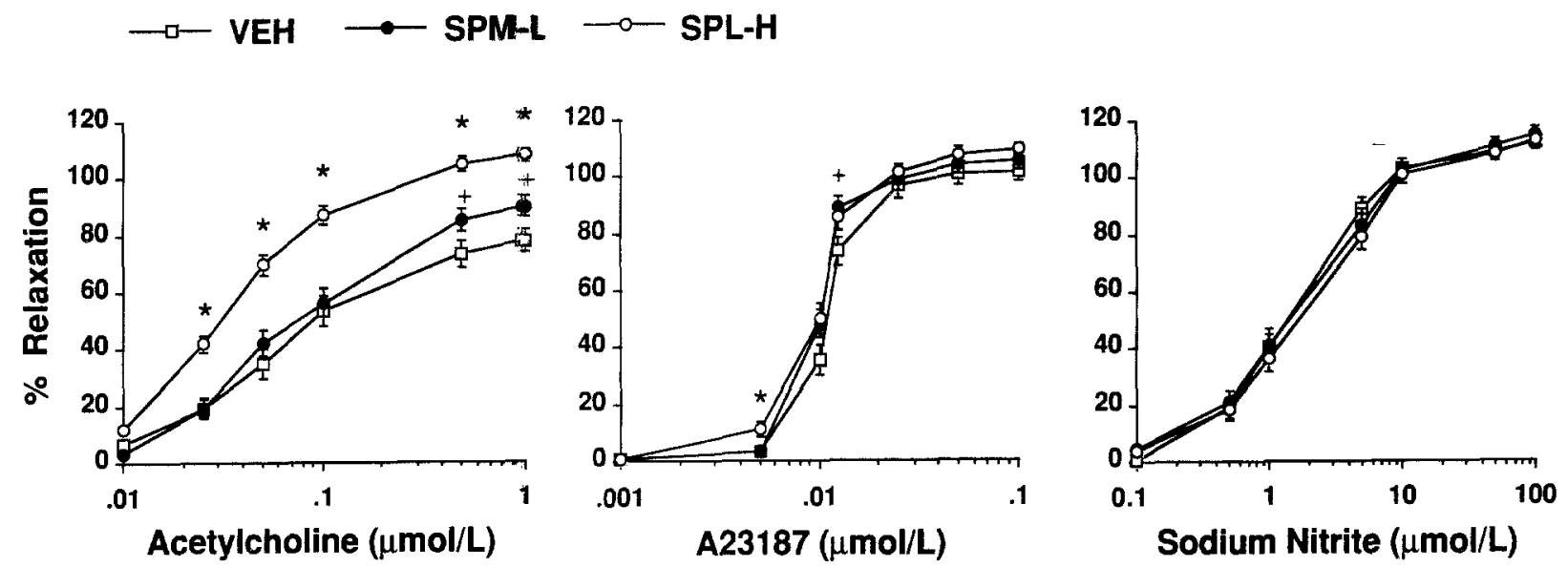

Fig. 4. Concentration response curves to acetylcholine, the calcium ionophore A23187, and acidified sodium nitrite in coronary arterial rings from each group. Values are expressed as percent change in tension from precontraction with thromboxane $A_{2}$ analogue U46619. Asterisk, $p<0.05$ versus VEH and SPM-L; plus sign, $p<0.05$ versus VEH.

lium are thought to be key factors in postischemic injury in that activated neutrophils generate oxygenderived free radical species, ${ }^{26}$ release proteolytic enzymes, and aggregate and embolize in the microvasculature. In fact, adherence of neutrophils to the coronary vascular endothelium is thought to be a prerequisite for neutrophil-induced inflammatory damage. ${ }^{27}$ SPM-5185, as an organic donor of NO, may inhibit the aforementioned sequence of events in the cascade of neutrophil-induced damage. NO inhibits adherence of neutrophils to the coronary endothelium, ${ }^{28,29}$ whereas inhibition of NO production by L-nitro-monomethyl arginine ${ }^{7}$ or reperfusion injury ${ }^{30}$ increases neutrophil adherence. Furthermore, NO directly reduces oxyradical generation by neutrophils ${ }^{31}$ and may inactivate superoxide anions by biradical quenching. ${ }^{32}$

The role of NO in the setting of myocardial ischemic-reperfusion injury is intensely controversial, with some studies (including the present study) attributing a beneficial effect ${ }^{4,28,33-35}$ and others showing a deleterious effect. ${ }^{36-39}$ The study of Matheis and associates ${ }^{39}$ for example, showed that inhibition of endogenous NO improved posthypoxic functional recovery, thereby indirectly supporting a deleterious role for NO. The mechanisms underlying these purported deleterious effects include the breakdown of NO to peroxynitrite and hydroxyl radicals. ${ }^{37,40}$ However, other studies have not shown NO to be cytotoxic, even in the presence of peroxynitrite derivatives. ${ }^{41}$ The controversy may be related to dose-dependent effects of NO or differing roles of NO in ischemic-reperfused myocardium as opposed to hypoxic myocardium or shock states. Because NO synthase and hence the production of $\mathrm{NO}$ are dependent on the presence of oxygen, the level of substrate oxygen in the various models may be a factor that determines when (for example, ischemia with scant oxygen supply and reperfusion with adequate oxygen supply) and how much NO is produced. In addition, recent evidence suggests that peroxynitrite is "recycled" to nitrosothiols or NO itself in in vivo environments, instead of producing hydroxyl and nitrogen dioxide radicals. ${ }^{42}$ The present study adds to the body of data that support a beneficial effect of $\mathrm{NO}$, even at relatively high concentrations achieved by an exogenous NO donor.

The endothelium is a pivotal interface between the vascular space and myocardial parenchyma because it is the site of initiation of neutrophil activation, which touches off emigration into the interstitium and subsequent neutrophil-mediated damage to the myocyte. This role of the endothelium would link endothelial dysfunction, neutrophil activation, and contractile dysfunction as related events. Our data showing endothelial injury, neutrophil accumulation, and postischemic contractile dysfunction are consistent with this sequence of events. Indeed, we found that the degree of endothelial injury and postischemic contractile dysfunction were moderately correlated, but with a definite trend. An improved correlation may be obtained if endothelial injury across the microvasculature and the macrovasculature is correlated inasmuch as small vessels and capillaries may be more sensitive to endothelial injury that larger conductance vessels. In addition, 
a better correlation may be derived if coronary venous endothelial dysfunction is correlated with contractile dysfunction because neutrophils adhere to and emigrate predominantly through the coronary veins. ${ }^{43}$

In summary, the present study demonstrates that the addition of the NO donor SPM-5185 in BCP preserves postischemic left ventricular function and coronary endothelial function in canine hearts subjected to antecedent normothermic global ischemia and cardioplegic arrest and reperfusion. The degree of protection was dose dependent inasmuch as SPM5185 at a concentration of $1 \mu \mathrm{mol} / \mathrm{L}$ in BCP showed partial protection whereas $10 \mu \mathrm{mol} / \mathrm{L}$ demonstrated full recovery after ischemia. Because these cytoprotective effects of SPM-5185 were associated with reduction of neutrophil accumulation in the myocardium, the mechanism of this protection appears to be related to inhibition of neutrophils. However, further studies are necessary to determine the precise mechanisms of cytoprotection by SPM-5185 in cardioplegic arrest and reperfusion. It would also be interesting to investigate whether normothermic induction cardioplegia would enhance the cardioprotection of an NO donor by accelerating biochemical interactions between $\mathrm{NO}$ and neutrophils. In addition, it is not clear from the present study whether SPM-5185 exerts its protection during the period of cardioplegic ischemia or during the subsequent period of reperfusion. Finally, it would be interesting to determine whether NO donor therapy in the absence of cardioplegic ischemia would avoid postischemic injury, which would further confirm a role for NO donors in the attenuation of reperfusion injury.

We are grateful to Dr. Martin Feelisch of Schwarz Pharma AG, Monheim, Germany, and David J. Lefer, $\mathrm{PhD}$, for the generous supply of SPM-5185. We also thank Ms. Sharon Ireland for preparation of the manuscript and Dr. David J. Lefer for initiating our interest in vascular endothelial biology and NO donors.

\section{REFERENCES}

1. Ku DD. Coronary vascular reactivity after acute myocardial ischemia. Science 1982;218:576-8.

2. VanBenthuysen KM, McMurtry IF, Horwitz LD. Reperfusion after acute coronary occlusion in dogs impairs endothelium-dependent relaxation to acetylcholine and augments contractile reactivity in vitro. J Clin Invest 1987;79:265-74.

3. Tsao PS, Aoki N, Lefer DJ, Johnson G III, Lefer AM. Time course of endothelial dysfunction and myocardial injury during myocardial ischemia and reperfusion in the cat. Circulation 1990;82:1402-12.

4. Nakanishi K, Vinten-Johansen J, Lefer DJ, Fowler
WC III, McGee DS, Johnston WE. Intracoronary L-arginine during reperfusion improves endothelial function and reduces infarct size. Am J Physiol 1992; 263:H1650-8.

5. Palmer RMJ, Ferrige AG, Moncada S. Nitric oxide release accounts for biological activity of endothelium-derived relaxing factor. Nature 1987;327:525-6.

6. Furlong B, Henderson AM, Lewis MJ, Smith JA. Endothelium-derived relaxing factor inhibits in vitro platelet aggregation. Br J Pharmacol 1987;90:687-92.

7. Kubes P, Suzuki M, Granger N. Nitric oxide: an endogenous modulator of leukocyte adhesion. Proc Natl Acad Sci U S A 1991;88:4651-5.

8. Gryglewski RJ, Palmer RMJ, Moncada S. Superoxide anion is involved in the breakdown of endotheliumderived relaxing factor. Nature 1986;320:454-60.

9. Rubanyi GM, Vanhoutte PM. Superoxide anions and hyperoxia inactivate endothelium-derived relaxing factor. Am J Physiol 1986;250:H822-7.

10. McCord JM. Oxygen-derived free radicals in postischemic tissue injury. N Engl J Med 1985;312:159-63.

11. Pearson PJ, Lin PJ, Schaff HV. Global myocardial ischemia and reperfusion impair endothelium-dependent relaxations to aggregating platelets in the canine coronary artery. J THORAC CARDIOVASC SuRG 1992; 103:1147-54

12. Nakanishi K, Zhao ZQ, Vinten-Johansen J, Lewis JC, McGee DS, Hammon JW Jr. Coronary artery endothelial dysfunction after ischemia, blood cardioplegia, and reperfusion. Ann Thorac Surg 1994;58:191-9.

13. Johnson G III, Tsao PS, Lefer AM. Cardioprotective effects of authentic nitric oxide in myocardial ischemia with reperfusion. Crit Care Med 1991;19:244-52.

14. Lefer DJ, Nakanishi K, Vinten-Johansen J. Endothelial and myocardial cell protection by a cysteine-containing nitric oxide donor after myocardial ischemia and reperfusion. J Cardiovasc Pharmacol 1993;22:S34-43.

15. Vinten-Johansen J, Nakanishi $K$, Zhao ZQ, McGee DS, Tan P. Acadesine improves surgical myocardial protection with blood cardioplegia in ischemically injured canine hearts. Circulation 1993;88(Suppl):II350-9.

16. Hudspeth DA, Nakanishi K, Vinten-Johansen J, et al. Adenosine-enhanced blood cardioplegia avoids postischemic systolic dysfunction in ischemically injured hearts. Ann Thorac Surg [In press].

17. Tan P, Klopfenstein HS, Vinten-Johansen J. Interactive software for analysis of global or segmental cardiac systolic and diastolic performance by pressure-volume (dimension) relations [Abstract]. J Am Coll Cardiol 1993;21:15A.

18. Toombs CF, Vinten-Johansen J, Yokoyama $H$, Johnston WE, Julian JS, Cordell AR. Nonlinearity of indexes of left ventricular performance: effects on estimation of slope and diameter axis intercepts. Am J Physiol 1991;260:H1802-9.

19. Glower DD, Spratt JA, Snow ND. Linearity of the 
Frank-Starling relationship in the intact heart: the concept of preload recruitable stroke work. Circulation 1985;71:994-1009.

20. Nakanishi K, Lefer DJ, Johnston WE, Vinten-Johansen J. Transient hypocalcemia during the initial phase of reperfusion extends myocardial necrosis after 2 hours of coronary occlusion. Coron Artery Dis 1991;2:1009-21.

21. Mullane KM, Kraemer R, Smith B. Myeloperoxidase activity as a quantitative assessment of neutrophil infiltration into ischemic myocardium. J Pharmacol Methods 1985;14:157-67.

22. Follette DM, Buckberg GD, Mulder DG, Fonkalsrud EW. Deleterious effects of crystalloid hyperkalemic cardioplegic solutions on arterial endothelial cells. Surg Forum 1980;31:253-5.

23. Harjula A, Mattila S, Mattila I, et al. Coronary endothelial damage after crystalloid cardioplegia. J Cardiovasc Surg 1984;25:147-52.

24. Saldanha C, Hearse DJ. Coronary vascular responsiveness to 5-hydroxytryptamine before and after infusion of hyperkalemic crystalloid solution in the rat heart. J ThORAC Cardiovasc SuRg 1989;98:783-7.

25. Nilsson FN, Miller VM, Vanhoutte PM, McGregor CGA. Methods of cardiac preservation alter the function of the endothelium in porcine coronary arteries. J Thorac Cardiovasc Surg 1991;102:923-30.

26. Lucchesi BR. Modulation of leukocyte-mediated myocardial reperfusion injury. Annu Rev Physiol 1990;52:561-76.

27. Mullane K. Neutrophil and endothelial changes in reperfusion injury. Trends Cardiovasc Med 1991;1:282-9.

28. Lefer DJ, Nakanishi K, Johnston WE, Vinten-Johansen J. Antineutrophil and myocardial protection actions of a novel nitric oxide donor after acute myocardial ischemia and reperfusion in dogs. Circulation 1993;88:2337-50.

29. Ma X, Lefer AM, Zipkin RE. S-nitroso- $N$-acetylpenicillamine is a potent inhibitor of neutrophil-endothelial interaction. Endothel 1993.

30. Ma X, Weyrich AS, Lefer DJ, Lefer AM. Diminished basal nitric oxide release after myocardial ischemia and reperfusion promotes neutrophil adherence to coronary endothelium. Circ Res 1993;72:403-12.

31. Clancy RM, Leszczynska-Piziak J, Abramson SB. Nitric oxide, an endothelial cell relaxation factor, inhibits neutrophil superoxide anion production via a direct action on the NADPH oxidase. J Clin Invest 1992;90:1116-21.

32. Rubanyi GM, Ho EH, Cantor EH, Lumma WC,
Parker-Botelho LH. Cytoprotective functions of nitric oxide: inactivation of superoxide radicals produced by human leukocytes. Biochem Biophys Res Commun 1989;181:1392-7.

33. Siegfried MR, Erhardt J, Rider T, Ma X, Lefer AM. Cardioprotection and attenuation of endothelial dysfunction by organic nitric oxide donors in myocardial ischemia-reperfusion. J Pharmacol Exp Ther 1992; 260:668-75.

34. Johnson G III, Tsao PS, Mulloy D, Lefer AM. Cardioprotective effects of acidified sodium nitrite in myocardial ischemia with reperfusion. J Pharmacol Exp Ther 1990;252:35-41.

35. Johnson G, Furlong LE, Aoki N, Lefer AM. Endothelium and myocardial protecting actions of taprostene, a stable prostacyclin analogue, after acute myocardial ischemia and reperfusion injury in cats. Circ Res 1990;66:1362-70.

36. Radi R, Beckman JS, Bush KM, Freeman BA. Peroxynitrite-induced membrane lipid peroxidation: the cytotoxic potential of superoxide and nitric oxide. Arch Biochem Biophys 1991;288:481-7.

37. Beckman JS, Crow JP. Pathological implications of nitric oxide, superoxide and peroxynitrite formation. Biochem Soc Trans 1993;21:330-4.

38. Rubio R, Berne RM, Katori M. Release of adenosine in reactive hyperemia of the dog heart. Am J Physiol 1969;216:56-62.

39. Matheis G, Sherman MP, Buckberg GD, Haybron DM, Young HH, Ignarro LJ. Role of L-arginine-nitric oxide pathway in myocardial reoxygenation injury. Am J Physiol 1992;262:H616-20.

40. Beckman JS, Beckman TW, Chen J, Marshall PA, Freeman BA. Apparent hydroxyl radical production by peroxynitrite: implications for endothelial injury from nitric oxide and superoxide. Proc Natl Acad Sci U S A 1990;87:1620-4.

41. Wink DA, Hanbauer I, Krishna MC, DeGraff W, Gamson J, Mitchell JB. Nitric oxide protects against cellular damage and cytotoxicity from reactive oxygen species. Proc Natl Acad Sci U S A 1993;90:9813-7.

42. Moro MA, Darley-Usmar VM, Goodwin DA, et al. Paradoxical fate and biological action of peroxynitrite on human platelets. Proc Natl Acad Sci U S A 1994;91: 6702-6.

43. Lefer DJ, Nakanishi K, Vinten-Johansen J, Ma X, Lefer AM. Cardiac venous endothelial dysfunction after myocardial ischemia and reperfusion in dogs. Am J Physiol 1992;263:H850-6. 